\title{
Cancer Risks from Arsenic in Drinking Water
}

\author{
by Allan H. Smith, ${ }^{1}$ Claudia Hopenhayn-Rich, ${ }^{1}$ \\ Michael N. Bates, ${ }^{1}$ Helen M. Goeden, ${ }^{1}$ Irva Hertz- \\ Picciotto, ${ }^{2}$ Heather M. Duggan, ${ }^{1}$ Rose Wood, ${ }^{3}$ \\ Michael J. Kosnett, ${ }^{4}$ and Martyn T. Smith'
}

\begin{abstract}
Ingestion of arsenic, both from water supplies and medicinal preparations, is known to cause skin cancer. The evidence assessed here indicates that arsenic can also cause liver, lung, kidney, and bladder cancer and that the population cancer risks due to arsenic in U.S. water supplies may be comparable to those from environmental tobacco smoke and radon in homes. Large population studies in an area of Taiwan with high arsenic levels in well water $(170-800 \mu \mathrm{g} / \mathrm{L})$ were used to establish dose-response relationships between cancer risks and the concentration of inorganic arsenic naturally present in water supplies. It was estimated that at the current EPA standard of $50 \mu \mathrm{g} / \mathrm{L}$, the lifetime risk of dying from cancer of the liver, lung, kidney, or bladder from drinking $1 \mathrm{~L} /$ day of water could be as high as 13 per 1000 persons. It has been estimated that more than 350,000 people in the United States may be supplied with water containing more than $50 \mu \mathrm{g} / \mathrm{L}$ arsenic, and more than 2.5 million people may be supplied with water with levels above $25 \mu \mathrm{g} / \mathrm{L}$. For average arsenic levels and water consumption patterns in the United States, the risk estimate was around 1/1000. Although further research is needed to validate these findings, measures to reduce arsenic levels in water supplies should be considered.
\end{abstract}

\section{Introduction}

Arsenic is a ubiquitous element present in various compounds throughout the earth's crust. It was identified in ancient times; the Greek alchemist Olympiodorus reportedly obtained metallic arsenic by roasting one of its sulfides. The use of arsenical compounds increased greatly during the 18 th and 19 th centuries, including use in pigments and dyes, in preservatives of animal hides, in glass manufacture, agricultural pesticides, and various pharmaceutical substances.

The first described health effect, reported by Agricola in De Re Metallica in 1556 (1), involved arsenical cobalt, which ate away the skin of the hands of workmen. In 1888 Hutchison first described carcinoma of the skin in patients treated with arsenical mixtures for psoriasis and other skin conditions (2). Subsequent investigations have confirmed that ingestion of inorganic arsenic can cause skin cancer and that inhalation of inorganic arsenic can cause lung cancer (3).

\footnotetext{
'Department of Biomedical and Environmental Health Sciences, University of California, Berkeley, Berkeley, CA 94720.

${ }^{2}$ Department of Epidemiology, University of North Carolina at Chapel Hill, Chapel Hill, NC 27599-7400.

${ }^{3}$ Health Risk Associates, Berkeley, CA 94704.

${ }^{4}$ Occupational Health Clinic, San Francisco General Hospital, San Francisco, CA 94110.

Address reprint requests to A. H. Smith, Department of Biomedical and Environmental Health Sciences, 314 Warren Hall, University of California, Berkeley, CA 94720.
}

Both organic and inorganic arsenic are present in varying amounts in food. Fish, for example, contain relatively high concentrations of organic arsenic. However, inorganic forms of arsenic are much more toxic than the organic forms. Inorganic arsenic can be present as either arsenate $[\mathrm{As}(\mathrm{V})]$ or arsenite [As(III)]. Although As(III) is more toxic, human metabolism of As(V) involves reduction to As(III) before undergoing detoxification by methylation (4).

Arsenic is present in soil at levels ranging from 0.2 to $40 \mu \mathrm{g} / \mathrm{g}$ (rarely more than $10 \mu \mathrm{g} / \mathrm{g}$ ) and in urban air at levels around 0.02 $\mu \mathrm{g} / \mathrm{m}^{3}(3)$, but for the general population the main exposure to inorganic arsenic is through ingestion. Although most major U.S. drinking water supplies contain levels lower than $5 \mu \mathrm{g} / \mathrm{L}$, it has been estimated that about 350,000 people might drink water containing more than $50 \mu \mathrm{g} / \mathrm{L}(5)$, the standard for arsenic set by the U.S. Environmental Protection Agency (EPA).

Cancer risk estimates attributed to ingested arsenic have been based on skin cancer risks alone. There is now sufficient evidence to consider other internal and more fatal cancers caused by ingested arsenic as well. The purpose of this paper is to present the findings of a cancer risk assessment of ingestion of inorganic arsenic in drinking water based on mortality from internal cancers.

Cancer risk assessments such as this one can be divided into four steps: hazard identification, dose-response analysis, exposure assessment, and risk characterization (6). The first section of this paper deals with hazard identification and presents 
evidence indicating that, in addition to the well-known association with skin cancer, ingestion of arsenic may also cause liver, lung, bladder, and kidney cancer. A dose-response analysis and risk extrapolation based on epidemiological studies of populations exposed to elevated levels of inorganic arsenic in their drinking water follow, along with an assessment of the possibility of a threshold (i.e., a level of exposure below which there would be no increase in population cancer risks). Exposure data are then described concerning the levels of arsenic in U.S. water supplies. Finally, results of risk characterization are presented, and the estimates of cancer risks from ingestion of arsenic in U.S. drinking water are compared with those from two other high-risk environmental exposures: environmental tobacco smoke and radon.

\section{Hazard Identification}

The main sources of evidence for the carcinogenicity of ingested inorganic arsenic come from human studies, with some limited evidence from animal studies. Results of human investigations are described first, followed by those of animal experiments.

\section{Human Studies}

Inhalation of inorganic arsenic has been shown to cause lung cancer in studies of smelter workers (3). However, evidence considered below suggests that systemic absorption by these workers was insufficient to identify significantly increased risks of cancers at other sites. Much higher systemic exposures have occurred among populations ingesting water with high arsenic concentrations, and studies of such populations have shown increased risks of skin, liver, lung, bladder, and kidney cancers.

The plausibility of a causal association is supported by exposure studies that found arsenic concentrations in skin, liver, lung, and kidney tissues (7). Animal studies generally show arsenic to accumulate at these sites (8-12). Studies of arsenic in humans exposed to background levels have found varying concentrations in different organs, including skin, lung, liver, and kidney $(13,14)$. This section presents a brief overview of the skin cancer evidence, and a more detailed analysis of the less publicized evidence linking ingestion of inorganic arsenic with cancer at the other more fatal sites.

Skin Cancer. Substantial evidence led the International Agency for Research on Cancer (IARC) to conclude that ingestion of inorganic arsenic can cause skin cancer (3). Populations in countries such as Taiwan, Mexico, India, and Chile who consumed drinking water with high levels of arsenic had high rates of skin cancer (15-18). In Taiwan, the prevalence of skin cancer among highly exposed males aged 60 years and older reached $25 \%$ (15). There are also many corroborating reports of skin cancer cases resulting from the use of orally administered arsenical medications, particularly Fowler's solution, which was widely used for the treatment of a variety of conditions such as asthma and psoriasis (19-22).

Liver Cancer. Angiosarcoma of the liver is a very rare tumor, often associated with exposure to vinyl chloride or thorotrast. It is estimated that only about 25 cases occur in the United States each year (23). In light of its rarity, even a small number of angiosarcoma cases associated with exposure to arsenic must be considered meaningful.
In 1957, Roth reported three cases of liver angiosarcoma in a series of 27 autopsies performed between 1950 and 1956 among arsenic-poisoned German vintners (24). A study in Chile found that among a group of 16 male cancer patients exposed to high arsenic levels through the water supply (200-2000 $\mu \mathrm{g} / \mathrm{L}), 15 \mathrm{had}$ skin carcinomas and one had a liver angiosarcoma in addition to chronic arsenical dermatosis (25).

Falk et al. identified 168 cases of liver angiosarcoma in the United States between 1964 and 1974 (26), of whom 7 had used Fowler's solution for 6-17 years. Other individual case reports of liver angiosarcoma associated with medicinal ingestion of arsenic have also been published $(23,27,28)$.

Increased mortality from primary liver cancer has also been associated with arsenic ingestion in several studies. Luchtrath compared the autopsy findings of 163 German winegrowers diagnosed as having chronic arsenic poisoning with those of a control group of 163 men of similar age (29). The winegrowers had been heavily exposed to arsenic through drinking Haustrunk, a wine substitute made from an aqueous infusion of grapes that had a high arsenic content. Liver cancers were found in five of the winegrowers but in none of the control group. These findings are consistent with an arsenic effect but are difficult to interpret due to possible confounding with alcohol intake.

Several epidemiological studies based on data from an area of southwestern Taiwan known to have high levels of inorganic arsenic in the artesian well water supply have found elevated rates of liver cancer deaths. The most striking findings come from a study in which the population was classified into three groups according to the arsenic level in their drinking water (300, 300-600, and $>600 \mu \mathrm{g} / \mathrm{L})(30,31)$. Using the number of wells in each category and their arsenic concentrations, the EPA calculated the weighted averages for each of the three groups to be 170,470, and $800 \mu \mathrm{g} / \mathrm{L}$ (32). From the data given by Chen et al. (30), an increasing mortality rate ratio for liver cancer can be calculated with increasing arsenic concentration: $1.2,1.5$, and 2.5 for males $(p<0.001)$ and 1.6, 2.1, and 3.6 for females $(p<0.001)$ (Table 1$)$. The similarities between residents of neighboring villages with respect to diets, sociodemographic characteristics, and lifestyle make it unlikely that confounding could explain the association between water arsenic concentrations and cancer rates.

These results are supported by $a$ ) a case-control study in the same area that reported a strong relationship between years of

Table 1. Estimated mortality risk ratios for liver, lung, bladder, and kidney cancer by arsenic levels in drinking water in̈ southwestern Taiwan, using cancer mortality rates of the general Taiwanese population as reference."

\begin{tabular}{|c|c|c|c|c|c|c|}
\hline \multirow{2}{*}{$\begin{array}{l}\text { Cancer } \\
\text { site }\end{array}$} & \multirow[b]{2}{*}{ Sex } & \multicolumn{4}{|c|}{ Water levels, $\mu \mathrm{g} / \mathrm{L}$} & \multirow{2}{*}{$\begin{array}{l}p \text {-Value for } \\
\text { linear trend }\end{array}$} \\
\hline & & Background & 170 & 470 & 800 & \\
\hline \multirow[t]{2}{*}{$\overline{\text { Liver }}$} & $\mathbf{M}$ & 1.0 & 1.2 & 1.5 & 2.5 & $<0.001$ \\
\hline & $\mathbf{F}$ & 1.0 & 1.6 & 2.1 & 3.6 & $<0.001$ \\
\hline \multirow[t]{2}{*}{ Lung } & $\mathbf{M}$ & 1.0 & 1.8 & 3.3 & 4.5 & $<0.001$ \\
\hline & $\mathbf{F}$ & 1.0 & 2.8 & 4.3 & 8.8 & $<0.001$ \\
\hline \multirow[t]{2}{*}{ Bladder } & $\mathbf{M}$ & 1.0 & 5.1 & 12.1 & 28.7 & $<0.001$ \\
\hline & $\mathbf{F}$ & 1.0 & 11.9 & 25.1 & 65.4 & $<0.001$ \\
\hline \multirow[t]{2}{*}{ Kidney } & $\mathbf{M}$ & 1.0 & 4.9 & 11.9 & 19.6 & $<0.001$ \\
\hline & $\mathbf{F}$ & 1.0 & 4.0 & 13.9 & 37.0 & $<0.001$ \\
\hline
\end{tabular}

abased on data from Chen et al. (30). 
consumption of well water and liver cancer $(33) ; b)$ a comparison of site-specific cancer mortality rates in the population of the high arsenic area with those of the general Taiwanese population (34);c) an investigation of cancer mortality of patients who suffered from blackfoot disease (BFD), a vascular disorder endemic to southwestern Taiwan and associated with the use of arsenic-rich artesian well water (35); and $d$ ) an ecological study of cancer mortality rates and arsenic levels in the drinking water of 314 townships in Taiwan (36).

In summary, a causal association between ingested arsenic and liver cancer is supported by a series of case reports concerning angiosarcoma of the liver, an investigation of arsenic-poisoned winegrowers in Germany, and several studies in southwestern Taiwan where drinking water has a naturally high arsenic content.

Lung Cancer. Although inhaled arsenic is a well-known lung carcinogen (3), little attention has been given to the evidence relating lung cancer to arsenic ingestion. A number of case reports link lung cancer to cutaneous signs of arsenicism resulting from ingestion (28,37-39). For example, Robson and Jelliffe described six patients with both lung tumors and skin disease characteristic of arsenic exposure, all of whom had used medications containing arsenic (39). Case reports of a common cancer such as lung cancer are not convincing by themselves, but the following epidemiological studies provide strong additional evidence.

Lung cancer was found in 108 of the 163 arsenic-poisoned winegrowers in Germany compared to only 14 among the controls (29). Mortality data from the trade association listed 417 deaths of winegrowers, 242 of whom had lung carcinomas. Although the winegrowers had heavy exposure to arsenic by ingestion, the possibility that the exposures responsible for the lung cancers were at least partly from inhalation cannot be ruled out. However, it should be noted that 30 of the winegrowers in the case series had skin cancer, which has been clearly linked to high levels of ingested arsenic, but has not been found in studies of smelter workers who have high lung cancer risks from arsenic inhalation.

Because data on smoking were not available, one could argue that confounding by smoking might explain the results. However, a high mortality odds ratio (40) of 14.7 can be calculated from the study results, making it unlikely that smoking alone could explain the findings. The main weakness of Luchtrach's study (29) relates to the lack of information on the choice of study subjects so that selection bias cannot be ruled out.

A study in the province of Cordoba, Argentina, examined mortality records for all deaths occurring between 1949 and 1959 in areas with high arsenic in drinking water (average $600 \mu \mathrm{g} / \mathrm{L}$ ) and compared the cause-specific mortality rates to those of the entire province (41). Mortality from all cancers combined was found to be considerably higher than in the province as a whole ( $24 \%$ of all deaths compared to $15 \%$ ). Of the 556 deaths attributed to cancer, $35 \%$ were found to be of the respiratory organs. In addition, several other published reports have mentioned elevated rates of lung cancer among patients with arsenicrelated skin disorders in several areas of Argentina where levels of arsenic in drinking water are known to be high $(42,43)$. However, these findings can only be considered suggestive evidence because they are based on observations from der- matological practices, with little or no information on background rates, case selection, length and completeness of follow up, or smoking habits.

The studies in southwestern Taiwan, described above in the section on liver cancer, also show evidence of elevated lung cancer mortality rates. When the population in the arsenic-rich area was divided in three groups according to the arsenic levels in drinking water, a clear dose-response relationship was observed (30). As shown in Table 1, increasing water arsenic concentrations $(170,470$, and $800 \mu \mathrm{g} / \mathrm{L})$ resulted in mortality rate ratios for lung cancer of $1.8,3.3$, and 4.5 for males, and 2.8, 4.3 and 8.8 for females, respectively, using lung cancer mortality in the general Taiwanese population for comparison.

The results of the case-control study carried out in the same area showed a linear trend between lung cancer rates and years of exposure to well water $(p<0.01)$, which persisted in a multiple regression analysis that controlled for the effects of smoking (33). Similar findings were reported in other mortality studies in the same area $(34,35)$ and in the recent ecological study carried out in all of Taiwan (36). In summary, the results of epidemiological studies provide evidence that ingested inorganic arsenic increases the risk of lung cancer.

Kidney and Bladder Cancer. The Taiwanese investigation of cancer mortality described above also found a clear doseresponse relationship between arsenic water levels and bladder and kidney cancer (30). In order of increasing water arsenic concentrations $(170,470$, and $800 \mu \mathrm{g} / \mathrm{L})$, the corresponding mortality rate ratios for bladder cancer were 5.1, 12.1, and 28.7 for males, and 11.9, 25.1, and 65.4 for females, and for kidney cancer, 4.9, 11.9, and 19.6 for men and 4.0, 13.9, and 37.0 for women (see Table 1). As with liver and lung cancer, the findings were supported by a case-control study showing a dose-response relationship between bladder cancer and years of artesian well water consumption $(p<0.01)$ after controlling for the effects of smoking, tea consumption, and other dietary factors (33). Results of other studies in the same area of Taiwan provide additional support for the association (34-36,44).

The magnitude of the above mortality rate ratios for bladder and kidney cancers is such that confounding by some other risk factor is most unlikely to be the explanation. The evidence suggests a causal relationship. Similar associations have so far not been reported elsewhere in relation with arsenic ingestion, but no other populations of comparable size and exposure have been studied.

The mortality rate ratios for these two cancers are sufficiently high to ask why increased risks have not been consistently detected in studies of smelter workers. Based on urinary arsenic levels of workers in a large smelter study that reported marked increases in lung cancer due to arsenic inhalation (45), one can estimate an average cumulative absorbed dose of arsenic of approximately $3000 \mathrm{mg}$. This is less than half the cumulative dose achieved by a 60 -year-old worker drinking $2 \mathrm{~L}$ of water/day at the lowest exposure level $(170 \mu \mathrm{g} / \mathrm{L})$ in the studies in Taiwan. If, on the other hand, one considers the group of workers with highest cumulative exposure, the estimate of systemic absorption becomes comparable to that of Taiwan. However, rates of these cancers are not given. Thus the failure to detect significant increases in bladder and kidney cancer among smelter workers may be due to a combination of their lower systemic exposure to arsenic and lack of examination of the highest exposed groups. 
Nevertheless, the findings concerning arsenic smelters are not completely negative. A recent study of arsenic-poisoned workers and residents of a mining town in Japan found them to have significantly elevated rates of cancers of the bladder, kidney, and other urinary organs (standardized mortality ratio $[$ SMR] $=766$, 95\% confidence interval [C.I.] 136-2795) in addition to lung cancer (SMR $=566,95 \%$ C.I. 266-1119) (46). Although the urinary tract cancer SMR of 766 was based on only two cases, it is significant that both were accompanied by Bowen's disease (characterized by skin lesions and associated with arsenic ingestion). Further study of kidney and bladder cancer mortality among smelter workers by duration and intensity of exposure is warranted.

\section{Animal Studies}

Arsenic is unique in being the only established human carcinogen that has not been established as a carcinogen in rodents. The IARC concluded that the results of animal studies supply only limited evidence of carcinogenicity (47). Although most arsenic inhalation bioassays have produced negative results, two groups of investigators reported positive findings in experiments involving intratracheal administration of arsenic (48-50). Bioassays involving oral exposure to arsenic have produced inconclusive results. Studies in mice given drinking water with arsenic levels ranging from 4.0 to $100 \mathrm{mg} / \mathrm{L}$ did not show increased cancer rates (51-53).

The effects of arsenic have also been examined in mouse strains that have a high background incidence rate of spontaneous tumors. The results from these investigations have been inconsistent. In one study, sodium arsenite appeared to inhibit the development and growth of precancerous cell populations, but once tumors developed, the growth rate was faster and the incidence of multiple tumors and metastases was higher in the arsenic-treated animals $(54,55)$. In another study, trivalent or pentavalent arsenic given in drinking water in conjunction with urethane decreased the number and size of tumors $(56,57)$.

Another group of investigators reported increased kidney and liver tumors in rats treated with either trivalent or pentavalent arsenic (58-60). In their latest study, intact male Wistar rats were injected with either saline or $30 \mathrm{mg} / \mathrm{kg}$ of diethylnitrosamine (DEN), a known carcinogen. After 1 week each group was subdivided into four treatment groups receiving $0,160 \mathrm{mg} / \mathrm{L} \mathrm{As}(\mathrm{III})$, $160 \mathrm{mg} / \mathrm{L} \mathrm{As}(\mathrm{V})$, or $80 \mathrm{mg} / \mathrm{L}$ dimethylarsonic acid (DMA) in drinking water. The animals were sacrificed after 10, 15, or 24 months of exposure.

Based on limited statistical analysis, the authors concluded that As(III) and DMA were promoters for DEN-initiated hepatocellular carcinomas and that $\mathrm{As}(\mathrm{III})$ and $\mathrm{As}(\mathrm{V})$ were promoters for DEN-initiated renal tumors. Using data provided in the report, we have conducted additional analyses using the MantelHaenszel chi-square test (61). In view of the relatively small number of animals per group (Table 2), the treatment groups were pooled across sacrifice time points first and then across treatments. The results of this analysis show an increase in tumor incidence, both with and without DEN, for each form of arsenic. The overall effect of arsenic on liver neoplastic nodules and kidney tumors was not likely to be attributable to chance $(p=$ 0.012 and 0.013 , respectively). It is noteworthy that the increased
Table 2. Carcinogenic effects of arsenic on intact rats."

\begin{tabular}{lcccc}
\hline & \multicolumn{3}{c}{ Sacrifice time points, months } & \\
\cline { 2 - 4 } Treatment group & 10 & 15 & 24 & \\
\cline { 2 - 4 } -Value \\
\hline Liver neoplastic nodules & & & & \\
Saline control & $0 / 14^{\mathrm{b}}$ & $0 / 11$ & $0 / 16$ & \\
Saline + As(III) & $0 / 22$ & $0 / 22$ & $2 / 7$ & $0.08^{\mathrm{c}}$ \\
Saline + As(V) & $0 / 14$ & $0 / 16$ & $1 / 5$ & NA \\
Saline + DMA & $0 / 10$ & $0 / 21$ & $2 / 6$ & 0.06 \\
DEN control & $0 / 14$ & $1 / 8$ & $3 / 6$ & $<0.01^{\mathrm{c}}$ \\
DEN + As(III) & $0 / 13$ & $3 / 14$ & $5 / 6$ & $0.22^{\mathrm{d}}$ \\
DEN + As(V) & $0 / 9$ & $4 / 9$ & $4 / 7$ & $0.21^{\mathrm{d}}$ \\
DEN + DMA & $1 / 14$ & $2 / 11$ & $7 / 8$ & $0.11^{\mathrm{d}}$ \\
& & & & \\
Kidney tumors & & & & \\
Saline control & $1 / 14$ & $0 / 11$ & $1 / 16$ & \\
Saline + As(III) & $0 / 22$ & $2 / 22$ & $2 / 7$ & $0.28^{\mathrm{c}}$ \\
Saline + As(V) & $2 / 14$ & $0 / 16$ & $2 / 5$ & $0.12^{\mathrm{c}}$ \\
Saline + DMA & $0 / 10$ & $0 / 221$ & $1 / 6$ & $0.28^{\mathrm{c}}$ \\
DEN control & $0 / 14$ & $0 / 8$ & $2 / 6$ & $0.42^{\mathrm{c}}$ \\
DEN + As(III) & $3 / 13$ & $4 / 14$ & $2 / 6$ & $0.05^{\mathrm{d}}$ \\
DEN + As(V) & $3 / 10$ & $4 / 9$ & $4 / 7$ & $<0.01^{\mathrm{d}}$ \\
DEN + DMA & $1 / 14$ & $0 / 11$ & $3 / 8$ & $0.45^{\mathrm{d}}$ \\
\hline
\end{tabular}

Abbreviations: DMA, dimethylarsonic acid; DEN, diethylnitrosamine; NA, not available (insufficient cell size to perform test).

"Based on data from Sirachi et al. (60).

bumber of animals affected/number of animals in treatment group.

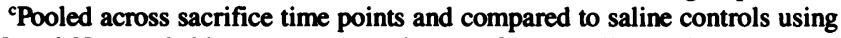
Mantel-Haenszel chi-square test ( $p$-values are for one-tailed testing).

${ }^{\text {}}$ Pooled across sacrifice time points and compared to DEN controls using Mantel-Haenszel chi-square test ( $p$-values are for one-tailed testing).

tumor incidence observed in rats occurred in liver and kidney, two of the target organs observed in humans. However, the fact that treated rats had significantly lower weights than control rats weakens the evidence from this study because it raises the possibility that increased cancer rates were an indirect effect of exposure affecting nutritional status.

The above data analysis provides some evidence that high doses of ingested arsenic may result in carcinogenic activity in rats. Although this effect was not seen in mice, the levels of arsenic in their drinking water were lower, and mice may be protected by methylating arsenic more rapidly than rats (62).

\section{Dose-Response Analysis}

\section{Skin Cancer}

Skin cancer risk estimates have been derived based on the study by Tseng et al., which involved a large population in the endemic area of Taiwan (15). Using skin cancer prevalence rates from populations having different arsenic levels in their drinking water, a clear dose-response relationship was observed. Brown et al. (63) calculated the lifetime risks of skin cancer to be 1.3/1000 for males and $0.6 / 1000$ for females per microgram of arsenic per day. In the section that follows, we examine the doseresponse relationships between arsenic levels in water and cancers of the lung, liver, bladder, and kidney and extrapolate the risk to the current U.S. drinking water standard of $50 \mu \mathrm{g} / \mathrm{L}$. We focus on these sites because mortality from these cancers is much higher than from skin cancer.

\section{Other Cancers}

Estimates of the risks of bladder, kidney, lung, and liver cancer were based on data from southwestern Taiwan, where a dose- 
response gradient between arsenic water levels and cancer mortality rates for these sites was observed (30). The statistical testing consisted of a trend analysis of proportions using linear regression (64). The well water concentrations were divided into three categories, with weighted average concentrations estimated to be 170,470 , and $800 \mu \mathrm{g} / \mathrm{L}(32)$. The mortality cancer rates reported by Chen et al. for the three arsenic levels were used (30), weighted by the person-years of exposure at each dose group, as given by Wu et al. (31), assuming that all cancer deaths for the four sites occurred in persons more than 20 years of age. The background population mortality rates for Taiwan were used as intercepts. The results of the regression analysis are shown in Table 3 and plotted in Figure 1, where it can be seen that the findings are reasonably consistent with linear dose-response relationships.

Table 3. Regression analysis of arsenic in drinking water and cancer mortality rates in Taiwan.

\begin{tabular}{lccccc}
\hline $\begin{array}{l}\text { Cancer } \\
\text { site }\end{array}$ & Sex & $\begin{array}{c}\text { Background } \\
\text { mortality }^{\mathrm{a}}\end{array}$ & $\begin{array}{c}\text { Slope } \\
\text { estimate }^{\mathrm{b}}\end{array}$ & $\begin{array}{c}\text { Standard error } \\
\text { of the slope }\end{array}$ & $\begin{array}{c}p \text {-Value for } \\
\text { linear trend }\end{array}$ \\
\hline Liver & $\mathrm{M}$ & 28.0 & 0.041 & 0.008 & $<0.001$ \\
& $\mathrm{~F}$ & 8.9 & 0.026 & 0.005 & $<0.001$ \\
Lung & $\mathrm{M}$ & 19.4 & 0.091 & 0.007 & $<0.001$ \\
& $\mathrm{~F}$ & 9.5 & 0.083 & 0.004 & $<0.001$ \\
Bladder & $\mathrm{M}$ & 3.1 & 0.083 & 0.003 & $<0.001$ \\
& $\mathrm{~F}$ & 1.4 & 0.091 & 0.002 & $<0.001$ \\
Kidney & $\mathrm{M}$ & 1.1 & 0.026 & 0.002 & $<0.001$ \\
& $\mathrm{~F}$ & 0.9 & 0.033 & 0.002 & $<0.001$ \\
\hline
\end{tabular}

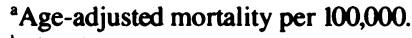

'The slope represents the increase in cancer mortality rate (per 100,000) per microgram increase of arsenic in drinking water, based on data from Chen et al. (30) and Wu et al. (31).

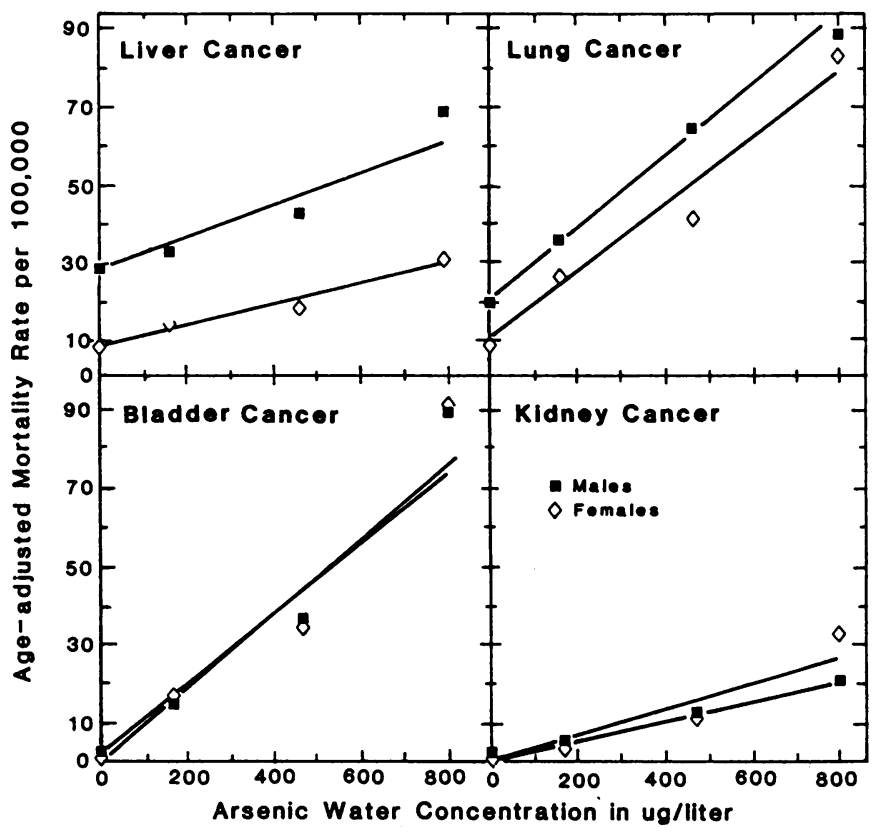

Figure 1. Age-adjusted mortality rates for liver, lung, bladder, and kidney cancer by the arsenic concentrations in drinking water and plots of linear regressions for data from studies in Taiwan $(30,31)$.

\section{Is There a Threshold?}

Inorganic arsenic is methylated into less toxic, organic forms at various sites in the body, in particular the liver and kidney. Urinary excretion of inorganic arsenic is thus a combination of unchanged inorganic arsenic and its methylated forms, DMA and MMA (dimethylarsonic and monomethylarsinic acids). It has been suggested that one might expect a threshold for the carcinogenic effect of arsenic ingestion if methylation activity had to be saturated before cancer risks increased $(32,65)$. If the carcinogenic effects of arsenic are caused only by the inorganic forms, and if ingested inorganic arsenic only reaches target organs when methylation is saturated, then one might expect a threshold for arsenic ingestion below which there would be no risk of it causing cancer. If, on the other hand, some inorganic arsenic always passes through the liver unchanged and reaches target organs, but the proportion remaining in inorganic form increased with increasing ingestion of arsenic, then one would expect a sublinear dose-response relationship between ingested arsenic and cancer risk.

A study in mice showed that increasing the dose of either As(III) or As(V) two orders of magnitude resulted in a 2- to 2.5-fold increase in the proportion excreted in the inorganic form (62). The data on methylation in humans, however, does not show evidence for such a relationship. Table 4 illustrates the distribution of urinary metabolites of inorganic arsenic excreted after different levels of exposure. Studies of individuals with background exposure found that unmethylated inorganic arsenic constituted between 15 and $32 \%$ of the urinary excretion of the metabolites of inorganic arsenic (66-70). Occupationally exposed populations had values within the same range $(67,69,70)$, as well as human volunteers who ingested measured doses of inorganic arsenic $(66,68,71)$. It can be clearly seen in Table 4 that even at low background levels of arsenic exposure methylation is far from complete.

Table 4. Relative distribution of urinary metabolites of inorganic arsenic (unchanged In-As, MMA, DMA) after exposure to different levels of inorganic arsenic.

\begin{tabular}{|c|c|c|c|c|c|}
\hline \multirow[b]{2}{*}{ Source of exposure } & \multirow{2}{*}{$\begin{array}{l}\text { Number } \\
\text { exposed }\end{array}$} & \multicolumn{3}{|c|}{ \% Excreted in urine ${ }^{a}$} & \multirow[b]{2}{*}{ Reference } \\
\hline & & In-As & MMA & DMA & \\
\hline \multirow[t]{6}{*}{ Background } & 148 & 32 & 32 & 36 & (67) \\
\hline & 4 & 18 & 4 & 78 & (66) \\
\hline & 16 & 18 & 4 & 78 & (68) \\
\hline & 6 & 18 & 16 & 65 & (69) \\
\hline & 41 & 15 & 20 & 66 & (70) \\
\hline & 102 & 23 & 7 & 70 & (80) \\
\hline \multicolumn{6}{|l|}{ Ocupational } \\
\hline Smelter workers & 9 & 19 & 20 & 61 & (69) \\
\hline Smelter workers & 30 & 20 & 22 & 66 & (70) \\
\hline Glass workers & 38 & 23 & 15 & 62 & (67) \\
\hline $\begin{array}{l}\text { Gallium arsenide } \\
\text { workers }\end{array}$ & 27 & 32 & 9 & 61 & (80) \\
\hline \multicolumn{6}{|c|}{ Experimental, $\mu \mathrm{g} / \mathrm{kg} / \mathrm{L}^{\mathrm{b}}$} \\
\hline 0.000143 & 6 & 27 & 21 & 51 & (71) \\
\hline 7.1 & 3 & 25 & 21 & 54 & (68) \\
\hline $9^{c}$ & 1 & 16 & 34 & 50 & (66) \\
\hline $18^{\mathrm{c}}$ & 1 & 7 & 20 & 73 & (66) \\
\hline $35.5^{\mathrm{c}}$ & 1 & 19 & 21 & 60 & (66) \\
\hline $71.5^{\mathrm{c}}$ & 1 & 26 & 32 & 42 & (66) \\
\hline
\end{tabular}

Abbreviations: In-As, inorganic arsenic; MMA, monomethylarsinic acid; DMA, dimethylarsonic acid.

${ }^{2}$ When a number exposed is $>1$, numbers represent group mean values. bexperimental doses are via ingestion of arsenic in water, assuming a body weight of $70 \mathrm{~kg}$ for human studies.

'Dose represents cumulative dose from 5 consecutive days. 
A recent paper (72) seems to contradict this evidence by showing that at low exposures methylation is near complete. However, it should be noted that this inference cannot be made based on the way the data were analyzed: nondetectable values were averaged in as zero. If, in fact, each inorganic arsenic species was just at the detection level of $0.5 \mu \mathrm{g} / \mathrm{L}$, then the total inorganic arsenic would be roughly around $20 \%$. Therefore, the evidence described above does not support a threshold for inorganic arsenic carcinogenicity.

\section{Exposure Assessment}

Current dietary intake of total arsenic in U.S. adults, excluding tap water, has been estimated to be around 45-50 $\mu \mathrm{g} /$ day $(32,73)$. Most of the arsenic derives from seafood, meat, and poultry (80\%) and grains and cereals (17\%). Although seafood has a high arsenic content, only about 5-10\% is in the inorganic form (74), and the organic forms (mainly arsenobetaine) are excreted unchanged (69). The EPA estimated the average total intake of inorganic arsenic from food, water and other beverages to be about $17 \mu \mathrm{g} /$ day, of which $5 \mu \mathrm{g} /$ day come from drinking water (32). Thus, for the majority of the U.S. population, about $30 \%$ of ingested inorganic arsenic comes from drinking water. However, if inorganic arsenic is present at the current water standard (50 $\mu \mathrm{g} / \mathrm{L})$, drinking water could contribute almost $100 \mu \mathrm{g}$ more to the daily intake of inorganic arsenic. This would represent about $90 \%$ of the daily intake. Even at half that concentration, water would still be by far the main source of inorganic arsenic (more than $80 \%$ ).

Based on several national water surveys, the EPA estimated the national occurrence of inorganic arsenic in drinking water (5). Although most public water supplies contain levels below 5 $\mu \mathrm{g} / \mathrm{L}$, it is estimated that about 350,000 people might drink water containing more than $50 \mu \mathrm{g} / \mathrm{L}$, and about $2,500,000$ people drink water containing more than $25 \mu \mathrm{g} / \mathrm{L}$.

\section{Risk Characterization}

\section{Risk Estimation for the U.S. Population}

The estimated mortality rate ratios for males and females are presented in Table 5. Risks for each cancer were extrapolated linearly to an arsenic concentration of $50 \mu \mathrm{g} / \mathrm{L}$ from the regression lines shown in Figure 1. Based on the EPA's assumption of daily water consumption rates of $3.5 \mathrm{~L}$ for men and $2.0 \mathrm{~L}$ for women in the hot climate of Taiwan (32), mortality rate ratios (RR) were calculated for a daily water intake of $1 \mathrm{~L} /$ day. The excess rate ratios, RR-1, were multiplied by the U.S. background rate (B), which was estimated by dividing the number of deaths from each cancer by the total number of deaths, using figures from U.S. Vital Statistics for the year 1985 (75). Lifetime risks of death from cancers of the liver, lung, bladder, and kidney were thus derived for consumption of $1 \mathrm{~L} /$ day in the United States (Table 5). The estimates of dying from one of these cancers due to a lifetime consumption of water containing $50 \mu \mathrm{g}$ of arsenic/L at a rate of $1 \mathrm{~L} /$ day were $9.4 / 1000$ for males and $17.3 / 1000$ for females, averaging around $13 / 1000$. It is important to emphasize that, contrary to most risk assessments of the type presented here, the calculation of risks involve only a small extrapolation from clearly demonstrated effects at $170 \mu \mathrm{g} / \mathrm{L}$ and above.
Table 5. Estimation of lifetime risks per 1000 of dying from cancer of the kidney, bladder, lung, and liver from consumption of $1 \mathrm{~L} /$ day of water with an arsenic concentration of $50 \mu \mathrm{g} / \mathrm{L}$.

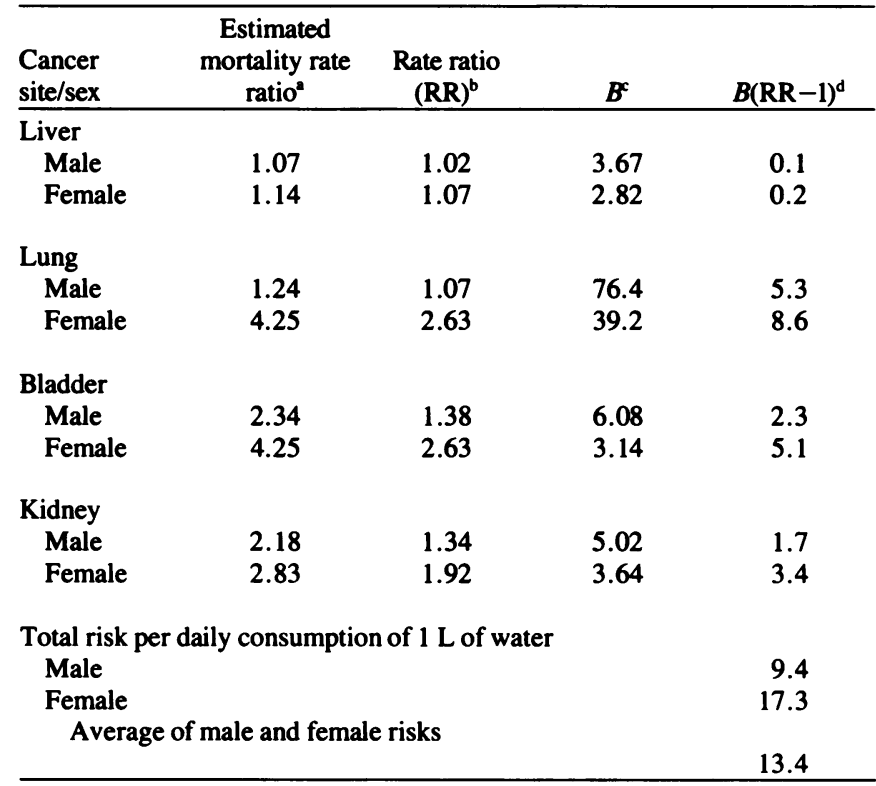

${ }^{2}$ Based on data from southwestern Taiwan $(30,31)$.

${ }^{\mathrm{b}} \mathrm{RR}=$ estimated mortality rate ratio calculated for water consumption of 1 L/day.

${ }^{\mathrm{C}} B=$ U.S. background risk per 1000 .

${ }^{\mathrm{d}} B(\mathrm{RR}-1)=$ lifetime risk per 1000 from water consumption of $1 \mathrm{~L} /$ day.

The male/female difference in risk estimation is due in part to the lower background cancer rates for women in Taiwan, thus making the rate ratios higher for those exposed. The EPA assumption that men in Taiwan drink almost twice as much water as women also decreases the estimated carcinogenic potency of arsenic for men compared to women. Nevertheless, the male/female risk estimate differences are within the range of uncertainty of a risk assessment such as the one presented here, and there is no biological reason to consider females to be at higher risk. For these reasons the male and female risks were averaged for application to the general population.

Although there are no accurate data on the average arsenic levels in drinking water for the United States, estimates range from 2.0 to $2.5 \mu \mathrm{g} / \mathrm{L}(7,32)$. Using the estimated average water intake in the United States of $1.6 \mathrm{~L} /$ day (76) and an average arsenic water level of $2.5 \mu \mathrm{g} / \mathrm{L}$, linear extrapolation yielded an estimated lifetime risk of dying from liver, lung, bladder or kidney cancer due to arsenic in drinking water of $1 / 1000$.

Some animal studies seem to indicate that a protein-deficient diet increases arsenic toxicity by decreasing methylation capacity $(8)$. It has been hypothesized that populations consuming inadequate diets and exposed to high arsenic levels may thus be more susceptible to arsenic toxicity (32). If nutritionally inadequate diets among the Taiwanese population exposed to arsenic made them more susceptible to the carcinogenic effects of arsenic, the extrapolated risk estimates for the average U.S. population would be too high. However, the validity of the Taiwanese findings would remain unchanged, as the populations in Taiwan drinking water with different levels of arsenic were all similar with respect to lifestyle, education, and occupation (33). Variation in the detoxification of arsenic by methylation, 
either due to nutritional or genetic factors, has not yet been investigated in humans and is an important area of research that needs to be addressed.

\section{Comparison with Cancer Risks from Other Environmental Exposures}

The estimates of cancer risks associated with the current U.S. drinking water standard derived above place arsenic at the forefront of cancer risks associated with environmental exposures. There are only two known environmental exposures with comparable risks, namely, environmental tobacco smoke (ETS) and radon in homes. In the case of ETS, exposure occurs from several sources, mainly from living with a smoker or working with smokers. The National Research Council estimates the lifetime risk of lung cancer attributable to ETS to range from 4 to $10 / 1000(77)$.

Considerable attention has been given in recent years to the increased risk of lung cancer caused by indoor radon exposure (78). Nero et al. (79) estimated that the average indoor concentration of radon in U.S. homes poses a lifetime lung cancer risk of about 3/1000. Table 6 compares the cancer risks from ETS, radon, and arsenic in drinking water.

\section{Evidence That Arsenic is a Beneficial Micronutrient}

Policy decisions arising from potential cancer risks due to inorganic arsenic in drinking water need to consider the possibility that arsenic is a beneficial micronutrient. Signs of arsenic deprivation, including depressed growth and abnormal reproductive function, have been described for the chicken, goat, pig, and rat (32), indicating the possibility that arsenic, at least in inorganic form, is an essential nutrient. Based on these experimental data, various estimates of human nutritional requirements have been made, ranging from 10 to $30 \mu \mathrm{g} /$ day (32). However, the relevance of the experimental animal data to humans is unclear. No human arsenic deficiency syndrome has yet been reported, even though many water supplies contain less than $2.5 \mu \mathrm{g} / \mathrm{L}$. In contrast to humans, rats sequester arsenic in red blood cells (11), and it is possible that the other animal species in the deprivation studies also differ from humans in arsenic storage and metabolism. Human requirements for inorganic arsenic warrant more investigation, but there is no evidence to suggest that deficiency effects would result from reducing levels of arsenic in water supplies containing above-average concentrations.

Table 6. Estimated lifetime risks of dying from cancer due to exposure to different environmental carcinogens in the United States.

\begin{tabular}{lr}
\hline Carcinogen & \multicolumn{1}{c}{ Risk } \\
\hline Environmental tobacco smoke (passive smoking) & \\
$\quad$ Low exposure (not married to a smoker) & $4 / 1000$ \\
High exposure (married to a smoker) & $10 / 1000$ \\
& \\
Radon in homes & $3 / 1000$ \\
$\quad$ Average exposure & $20 / 1000$ \\
High exposure (1-3\% of homes) & \\
& \\
Arsenic in drinking water (1.6 L/day) & $1 / 1000$ \\
$2.5 \mu \mathrm{g} / \mathrm{L}$ (U.S. estimated average) & $21 / 1000$ \\
$50 \mu \mathrm{g} / \mathrm{L}$ (U.S. water standard)
\end{tabular}

\section{Conclusions}

On the basis of the overall consistency of results from epidemiological studies, there is persuasive evidence that inorganic arsenic is a cause of human cancer at several sites. A causal association between ingested arsenic and skin cancer has previously been established. The evidence presented here strongly supports a causal relationship between ingested arsenic and both liver and lung cancer. There is also evidence from Taiwan that arsenic causes human kidney and bladder cancer, although further studies are needed to confirm these findings. Additional research also needs to be conducted concerning arsenic methylation and its relationship to genetic, dietary, or other lifestyle factors, which may affect individual differences in susceptibility to the carcinogenic effects of arsenic.

Although the drinking water of the majority of the U.S. population has levels of arsenic considerably below the standard, it is estimated that about 350,000 people drink water with levels above the standard, and more than 2.5 million people are supplied with water containing more than $25 \mu \mathrm{g} / \mathrm{L}$. The comparisons with ETS and radon, two recognized carcinogens of public health concern, serve to point out the serious environmental cancer risks posed by arsenic in drinking water. Although further research is needed to validate the findings of this risk assessment, measures should be taken to reduce arsenic levels in water supplies.

This work was funded in part by a contract with the California Department of Health Services. Additional support was received from the Health Effects component of the University of California Toxic Substances Program, the Center for Occupational and Environmental Health, University of California, and NIH grant P42-ES04705. We thank G. Alexeeff, B. Ames, C. Becker, L. Gold, E. Holly, M. Lipsett, and R. Spear for reviewing and commenting on the manuscript.

\section{REFERENCES}

1. Dibner, B. Agricola on Metals. Burndy Library, Norwalk, CT, 1958.

2. Hunter, D. The Diseases of Occupations. English Universities Press, London, 1957.

3. IARC. IARC Monographs on the Evaluation of the Carcinogenic Risk of Chemicals to Man: Some Metals and Metallic Compounds, Vol. 23. International Agency for Research on Cancer, Lyon, 1980.

4. Squibb, K. S., and Fowler, B. A. The toxicity of arsenic and its compounds. In: Biological and Environmental Effects of Arsenic (B. A. Fowler, Ed.), Elsevier, Amsterdam, 1983, pp. 233-269.

5. Science Applications International Corporation. Estimated National Occurrence and Exposure to Arsenic in Public Drinking Water Supplies. Revised Draft, prepared for U.S. Environmental Protection Agency under Contract no. 68-01-766. EPA, Washington, 1987.

6. National Research Council. Risk Assessment in the Federal Government: Managing the Process. National Academy Press, Washington, DC, 1983.

7. Life Systems, Inc. Toxicological Profile for Arsenic. Report No. ATSDR/TP-88/02 prepared for Agency for Toxic Substances and Disease Registry, Atlanta, GA, 1989.

8. Vahter, M., and Marafante, E. Effects of low dietary intake of methionine, choline or proteins on the biotransformation of arsenite in the rabbit. Toxicol. Lett. 37: 41-46 (1987).

9. Vahter, M., and Norin, H. Metabolism of ${ }^{74}$ As-labeled trivalent and pentavalent inorganic arsenic in mice and rats. Environ. Res. 21 : 446-457 (1980).

10. Marafante, E., Bertolero, F., Edel, J., Pietra, R., and Sabbioni, E. Intracellular interaction and biotransformation of arsenite in rats and rabbits. Sci. Total Environ. 24: 27-39 (1982). 
11. Vahter, M. Metabolism of arsenic. In: Biological and Environmental Effects of Arsenic (B. A. Fowler, Ed.), Elsevier, Amsterdam, 1983, pp. 171-198.

12. Yamauchi, H., and Yamamura, Y. Metabolism and excretion of orally administered arsenic trioxide in the hamster. Toxicology 34: 113-121 (1985).

13. Dang, H. S., Jaiswal, D. D., and Somasundaram, S. Distribution of arsenic in human tissues and milk. Sci. Total Environ. 29: 171-175 (1983).

14. Yamauchi, H., and Yamamura, Y. Concentration and chemical species of arsenic in human tissue. Bull. Environ. Contam. Toxicol. 31: 267-277 (1983).

15. Tseng, W. P., Chu, H. M., How, S. W., Fong, J. M., Lin C. S., and Yeh, S. Prevalence of skin cancer in an endemic area of chronic arsenicism in Taiwan. J. Natl. Cancer Inst. 40: 453-463 (1968).

16. Cebrian, M. E., Albores, A., Aquilar, M., and Blakely, E. Chronic arsenic poisoning in the North of Mexico. Hum. Toxicol. 2: 121-133 (1983).

17. Chakraborty, A. K., and Saha, K. C. Arsenical dermatosis from tubewell water in West Bengal. Indian J. Med. Res. 85: 326-334 (1987).

18. Zaldivar, R. Arsenic contamination of drinking water and food-stuffs causing endemic chronic poisoning. Beitr. Pathol. 151: 384-400 (1974).

19. Cuzick, J., Evans, S., Gillman, M., and Evans, D. A. Medicinal arsenic and internal malignancies. Br. J. Cancer 45: 904-911 (1982).

20. Sommers, S. C., and McManus, R. G. Multiple arsenical cancers of skin and internal organs. Cancer 6: 347-359 (1953).

21. Fierz, U. Katamnestische ontersuchungen ober die nebenwirkungen der therapie sit anorganisches arsen bei hautkrankheiten. Dermatologica 131: 41-58 (1965).

22. Tay, C. H. Cutaneous manifestations of arsenic poisoning due to a certain Chinese herbal medicine. Aust. J. Dermatol. 15: 121-131 (1974).

23. Roat, J. W., Wald, A., Mendelow, H., and Pataki, K. I. Hepatic angiosarcoma associated with short-term arsenic ingestion. Am. J. Med. 73: 933-936 (1982).

24. Roth, F. The sequelae of chronic arsenic poisoning in Moselle vintners. J. Med. Monthly 2: 172-175 (1957).

25. Zaldivar, R., Prumes, L., and Ghai, G. L. Arsenic dose in patients with cutaneous carcinomata and hepatic haemangioendothelioma after environmental and occupational exposure. Arch. Toxicol. 47: 145-154 (1981).

26. Falk, H., Caldwell, C. G., Ishak, K. G., Thomas, L. B., and Popper, H. Arsenic-related hepatic angiosarcoma. Am. J. Ind. Med. 2: 43-50 (1981).

27. Lander, J. J., Stanley, R. J., Sumner, H. W., Boswell, D. C., and Aach, R. D. Angiosarcoma of the liver associated with Fowler's solution (potassium arsenite). Environ. Mutagen. 68: 1582-1586 (1975).

28. Kasper, M. L., Schoenfield, L., Strom, R. L., and Theologides, A. Hepatic angiosarcoma and bronchioloalveolar carcinoma induced by Fowler's solution. J. Am. Med. Assoc. 252: 3407-3408 (1984).

29. Luchtrath, $H$. The consequences of chronic arsenic poisoning among Moselle wine growers. J. Cancer Res. Clin. Oncol. 105: 173-182 (1983).

30. Chen, C. J., Kuo, T. L., and Wu, M. M. Arsenic and cancers (letter). Lancet i: $414-415$ (1988).

31. Wu, M. M., Kuo, T. L., Hwang, Y. H., and Chen, C. J. Dose-response relation between arsenic well water and mortality from cancer. Am. J. Epidemiol. 130: 1123-1132 (1989).

32. Risk Assessment Forum. Special Report on Ingested Arsenic: Skin Cancer; Nutritional Essentiality. EPA/625/3-87/013, U.S. Environmental Protection Agency, Washington, DC, 1988.

33. Chen, C. J., Chuang, Y. C., You, S. L., and Lin, H. Y. A retrospective study on malignant neoplasms of bladder, lung and liver in Blackfoot disease endemic area in Taiwan. Br. J. Cancer 53: 399-405 (1986).

34. Chen, C. J., Chuang, Y. C., Lin, T. M., and Wu, H. Y. Malignant neoplasms among residents of a Blackfoot disease-endemic area in Taiwan: high-arsenic artesian well water and cancers. Cancer Res. 45: 5895-5899 (1985).

35. Chen, C. J., Wu, M. M., Lee, S. S., Wang, J. D., Cheng, S. H., and Wu, H. Y. Atherogenicity and carcinogenicity of high-arsenic artesian well water; multiple risk factors and related malignant neoplasms of Blackfoot disease. Arteriosclerosis 8: 452-460 (1988).

36. Chen, C. J., and Wang, C. J. Ecological correlation between arsenic level in well water and age-adjusted mortality from malignant neoplasms. Cancer Res. 50(17): 5470-5475 (1990).

37. Heddle, R., and Bryant, G. D. Small cell lung carcinoma and Bowen's disease 40 years after arsenic ingestion. Chest 84: 776-777 (1983).

38. Goldman, A. L. Lung cancer in Bowen's disease. Am. Rev. Respir. Dis. 108: 1205-1207 (1973).

39. Robson, A. O., and Jelliffe, A. M. Medicinal arsenic poisoning and lung cancer. Br. Med. J. 2: 207-209 (1963).

40. Miettinen, $Q$, and Wang J.-D. An alternative to the proportionate mortality ratio. Am. J. Epidemiol. 114: 144-148 (1981).
41. Bergoglio, R. M. Mortality from cancer in regions of arsenical waters of the province of Cordoba, Argentina. Prensa Med. Argent. 51: 9954-1008 (1964).

42. Tello, E. E. Hydro-arsenicisms: what is the Argentine chronic hydroarsenicism (HACREA)? Arch. Argent. Dermatol. 36: 197-216 (1986).

43. Biagini, R., Rivero, M., Salvador, M., and Cordoba, S. Chronic arsenism and lung cancer. Arch. Argent. Dermatol. 28: 151-158 (1978).

44. Chiang, H., Hong, C., Guo, H., Lee, E., and Chen, T. Comparative study on the high prevalence of bladder cancer in the Blackfoot disease endemic area in Taiwan. J. Formosan Med. Assoc. 87(11): 1074-1080 (1988).

45. Enterline, P. E., and Marsh, G. M. Cancer among workers exposed to arsenic and other substances in a copper smelter. Am. J. Epidemiol. 116: 895-911 (1982).

46. Tsuda, T., Nagira, T., Yamamoto, M., and Kume, Y. An epidemiological study on cancer in certified arsenic poisoning patients in Toroku. Ind. Health 28: 53-62 (1990).

47. IARC. IARC Monographs on the Evaluation of Carcinogenic Risks to Humans; Overall Evaluation of Carcinogenicity: An Updating of IARC Monographs Volumes 1 to 42. Supplement 7. International Agency for Research on Cancer, Lyon, 1987, pp. 100-106.

48. Pershagen, G., Nordberg, G., and Bjorklund, N. E. Carcinomas of the respiratory tract in hamsters given arsenic trioxide and/or benzo-a-pyrene by the pulmonary route. Environ. Res. 34: 227-241 (1984).

49. Pershagen, G., and Bjorklund, N. E. On the pulmonary tumorigenicity of arsenic trisulfide and calcium arsenate in hamsters. Cancer Lett. 27: 99-104 (1985).

50. Ishinishi, N., Yamamoto, A., Hisanaga, A., and Inamasu, T. Tumorigenicity of arsenic trioxide to the lung in Syrian golden hamsters by intermittent instillations. Cancer Lett. 21: 141-147 (1983).

51. Huepr, W. C., and Payne, W. W. Experimental studies in metal carcinogenesis. Arch. Environ. Health 5: 445-462 (1962).

52. Baroni, C., Van Esch, G. J., and Saffiotti, U. Carcinogenesis test of two inorganic arsenicals. Arch. Environ. Health 7: 668-674 (1963).

53. Kanisawa, M., and Schroeder, H. A. Life term studies on the effect of trace elements on spontaneous tumors in mice and rats. Cancer Res. 29: 892-895 (1969).

54. Schrauzer, G. N., and Ishmael, D. Effects of selenium and of arsenic on the genesis of spontaneous mammary tumors in inbred C3H mice. Ann. Clin. Lab. Sci. 4: 441-447 (1974).

55. Schrauzer, G. N., White D. A., McGinness, J. E., Schneider, C. J., and Bell, L. J. Arsenic and cancer: effects of joint administration of arsenite and selenite on the genesis of mammary adenocarcinoma in inbred female $\mathrm{C} 3 \mathrm{H} / \mathrm{St}$ mice. Bioinorgan. Chem. 9: 245-253 (1978).

56. Blakley, B. R. Alterations in urethan-induced adenoma formation in mice exposed to selenium and arsenic. Drug Nutr. Interact. 5: 97-102 (1987).

57. Blakley, B. R. The effect of arsenic on urethan-induced adenoma formation in Swiss mice. Can. J. Vet. Res. 51: 240-243 (1987).

58. Shirachi, D. Y., Johansen, J. P., McGowan, J. P., and Tu, S. H. Tumorigenic effect of sodium arsenite in rat kidney. Proc West. Pharmacol. Soc. 26: 413-415 (1983).

59. Shirachi, D. Y., Tu, S.-H., and McGowan, J. P. Carcinogenic Potential of Arsenic Compounds in Drinking Water. EPA/600/1-86/003 U.S. Environmental Protection Agency, Cincinnati, OH, 1986.

60. Shirachi, D. Y., Tu, S.-H., and McGowan, J. P. Carcinogenic Effects of Arsenic Compounds in Drinking Water. EPA/600/1-87/007 U.S. Environmental Protection Agency, Cincinnati, OH, 1987.

61. Mantel, N., and Haenszel, W. Statistical aspects of the analysis of data from retrospective studies of disease. J. Natl. Cancer Inst. 22: 719-748 (1959).

62. Vahter M. Biotransformation of trivalent and pentavalent inorganic arsenic in mice and rats. Environ. Res. 25: 286-293 (1981).

63. Brown, K. G., Boyle, K. E., Chen, C. W., and Gibb, H. J. A dose-response analysis of skin cancer from inorganic arsenic in drinking water. Risk Anal. 9: 519-528 (1989).

64. Rothman, K. J. Modern Epidemiology. Little, Brown and Company, Boston, 1986.

65. Marcus, W. L., and Rispin, A. S. Threshold carcinogenicity using arsenic as an example. In: Advances in Modern Environmental Toxicology: Risk Assessment and Risk Management of Industrial and Environmental Chemicals (C. R. Cothern and M. A. Mehlman, Eds.), Princeton Publishing Company, Princeton, NJ, 1988, pp. 133-158.

66. Buchet, J. P., Lauwerys, R., and Roels, H. Comparison of the urinary excretion of arsenic metabolites after a single oral dose of sodium arsenite, monomethylarsonate, or dimethylarsinate in man. Int. Arch. Occup. Environ. Health 48: 71-79 (1981). 
67. Foa, V., Colombi, A., Maroni, M., Buratti, M., and Calzaferri, G. The speciation of the chemical forms of arsenic in the biological monitoring of exposure to inorganic arsenic. Sci. Total Environ. 34: 241-259 (1983).

68. Buchet, J. P., Lauwerys, R., and Roels, H. Urinary excretion of inorganic arsenic and its metabolites after repeated ingestion of sodium metaarsenite by volunteers. Int. Arch. Occup. Environ. Health 48: 111-118 (1981).

69. Vahter, M. Environmental and occupational exposure to inorganic arsenic. Acta Pharmacol. Toxicol. 59: 31-34 (1986).

70. Smith, T., Crecelius, E., and Reading, J. Airborne arsenic exposure and excretion of methylated arsenic compounds. Environ. Health Perspect. 19: 89-93 (1977).

71. Tam, G. K. H., Charbonneau, S. M., Bryce, F., Pomroy, C., and Sandi, E. Metabolism of inorganic arsenic in humans following oral ingestion. Toxicol. Appl. Pharmacol. 50: 319-322 (1979).

72. Farmer, J. G., and Johnson, L. R. Assessment of occupational exposure to inorganic arsenic based on urinary concentrations and speciation of arsenic. Br. J. Ind. Med. 47: 342-348 (1990).

73. Gunderson, E. L. FDA Total Diet Study, April 1982-April 1984: Dietary intakes of pesticides, selected elements, and other chemicals. J. Assoc. Off. Anal. Chem. 71: 1200-1209 (1988).

74. Pershagen, G. Sources of exposure and biological effects of arsenic. In:
Environmental Carcinogens: Selected Methods of Analysis, Some Metals: As, $\mathrm{Be}, \mathrm{Cd}, \mathrm{Cr}, \mathrm{Ni}, \mathrm{Pb}, \mathrm{Se}, \mathrm{Zn}$ (L. Fishbein, Ed.), International Agency for Research on Cancer, Lyon, 1986, pp.45-61.

75. National Center for Health Statistics. Vital Statistics of the United States, Vol. 2, Mortality, Part A. Public Health Service, U.S. Department of Health and Human Services, Washington, DC, 1985.

76. Cotruvo, J. A. Drinking water standards and risk assessment. Regul. Toxicol. Pharmacol. 8: 288-299 (1988).

77. National Research Council. Environmental Tobacco Smoke: Measuring Exposures and Assessing Health Effects, National Academy Press, Washington, DC, 1986.

78. National Research Council. Health Risks of Radon and Other Internally Deposited Alpha-Emitters. BEIR IV, National Academy Press, Washington, DC, 1988.

79. Nero, A. V., Schwehr, M. B., Nazaroff, W. W., and Rezvan, K. L. Distribution of airborne radon-222 concentrations in U.S. homes. Science 234: 992-997 (1986).

80. Yamauchi, H., Takahashi, K., Masiko, M., and Yamamura, Y. Biological monitoring of arsenic exposure of gallium arsenide-and inorganic arsenicexposed workers by determination of inorganic arsenic and its metabolites in urine and hair. Am. Ind. Hyg. Assoc. J. 50(11): 606-612 (1989). 